\title{
3D Quantification of Pore Scale Geometrical Changes Using Synchrotron Computed Microtomography
}

\author{
D. Bernard' \\ 1 Institut de Chimie de la Matière Condensée de Bordeaux, ICMCB-CNRS, Université Bordeaux 1, \\ ICMCB, 87, avenue du Dr A. Schweitzer, 33608 Pessac Cedex - France \\ e-mail: bernard@icmcb-bordeaux.cnrs.fr
}

\begin{abstract}
Résumé - Quantification 3D des modifications géométriques à l'échelle du pore par microtomographie synchrotron - La microtomographie synchrotron est une technique non-destructive de caractérisation tridimensionnelle fournissant une cartographie 3D de $\mu$, le coefficient d'atténuation linéaire du matériau étudié. En chacun des voxels (élément de volume, par analogie avec pixel, élément d'image en 2D), la valeur de $\mu$ est la moyenne des coefficients d'atténuation des différents fluides et solides présents au moment de l'acquisition. Lorsque l'échantillon considéré est composé de matériaux ayant des valeurs de $\mu$ très différentes, il est possible, par segmentation, de transformer la cartographie de $\mu$ en une image 3D de distribution des différents matériaux. De plus, la microtomographie étant nondestructive, il est possible de modifier l'échantillon entre deux acquisitions et de suivre les évolutions induites en 3D avec une précision inégalable.

La microtomographie synchrotron a été utilisée pour caractériser les évolutions micro structurales tridimensionnelles de deux échantillons soumis à des processus différents. Dans le premier cas, un échantillon de poudre de borate de lithium est suivi lors du frittage naturel. Les modifications micro structurales sont mises en évidence ainsi qu'un changement de phase solide-solide qui est quantifié en 3D. Dans le second cas, ce sont les changements causés par la percolation réactive d'eau saturée en $\mathrm{CO}_{2}$ au travers d'un échantillon de carbonate naturel qui sont caractérisés. La procédure permettant de passer des données microtomographiques aux séries d'images 3D d'un même échantillon est présentée. Les résultats obtenus illustrent les possibilités offertes par cette technique quantitative d'imagerie 3D pour améliorer la compréhension des transports réactifs couplés multi-échelle ayant lieu au sein des matériaux poreux.
\end{abstract}

\footnotetext{
Abstract-3D Quantification of Pore Scale Geometrical Changes Using Synchrotron Computed Microtomography - Synchrotron microtomography is a non-destructive 3D-characterisation technique providing a three-dimensional mapping of $\mu$, the linear $X$-ray absorption coefficient of the material under investigation. At each voxel (volume element in $3 D$ images, by analogy to pixel, picture element in $2 D$ ) the value of $\mu$ is the average of the absorption coefficients of the different solids and fluids contained into it at the moment of acquisition. When the considered sample is composed of several materials having dissimilar $\mu$ values, it is possible, by segmentation, to transform the $\mu$ mapping into a $3 D$ image of the different constitutive materials. Furthermore, microtomography being non-destructive, it is possible to modify the sample between two acquisitions and to follow the induced evolutions in $3 D$ with an unrivalled precision.
} 
Synchrotron microtomography has been used to characterise the 3D-microstructure evolutions of two samples submitted to two different processes. In the first case a lithium borate powder sample is followed during natural sintering. Morphological changes are shown as well as a solid-solid phase change that is quantified in $3 D$. In the second case, the modifications induced by reactive percolation of $\mathrm{CO}_{2}$ saturated water within a natural limestone sample are characterized. The process permitting to proceed from the data acquired on the tomography beam line to a series of $3 D$ images of the same sample at the different stages of its evolution is presented. The obtained results illustrate the possibilities offered by this quantitative $3 D$ imaging technique to improve the understanding of multi-scale coupled reactive transport processes in porous materials.

\section{INTRODUCTION}

Generally speaking, tomography is an imaging technique that can be used to outline the interior of objects, and to measure their organisation in space and time in a nondestructive way.

It is based on the use of penetrating rays like X-rays, gamma rays or other electromagnetic or acoustic waves. By combining measurements in various directions and performing reconstruction calculations, it provides a map of the parameter characterising the used radiation for one or more sections of the studied object giving access to the inside of the body.

During the 20th century, numerous new non-destructive inspection techniques were based on X-rays and X-rays naturally became one of the most used tomography technique (Stanley, 1988).

Improvements in computers quickly led to the first machines used for medical purposes; X-ray scanners. More recently developed high energy $\mathrm{X}$-ray tubes and related sensors allow this technique to be applied in different industries for inspecting parts for sectors such as aircraft or automobiles. Industrial tomographs generally consist of an $\mathrm{X}$-ray generator (120 to $450 \mathrm{kV}$ ), a sensor system (gas detectors, scintillation detectors, etc.), a mechanism for placing and moving the studied object and a computer. Currently industrial machines permit the inspection of parts as heavy as $150 \mathrm{Kg}$ and having a diameter of $0.6 \mathrm{~m}$ and a height of $1 \mathrm{~m}$. Controllable maximum thickness reaches $300 \mathrm{~mm}$ for aluminium alloy and $120 \mathrm{~mm}$ for steel, with a density resolution of about $0.2 \%$ and a geometrical resolution of about $0.1 \mathrm{~mm}$. The main applications of those tomographs are the detection of defects in materials, the density and geometric measurements and the positioning inspections.

In this paper we want to focus on another type of X-ray tomography where the voxel size unit is the micron, i.e. microtomography. Such a resolution is now easily achieved thanks to the use of a synchrotron light source or of a micro focus X-ray source. Comparing two experimental set-ups like a synchrotron and a micro-focus tomograph is not really significant: on one side we have a circular storage ring (typical diameter $250 \mathrm{~m}$ ) and several devices (typically 30) producing very intense synchrotron radiation beams that are used in large heavily protected experimental rooms, and on the other side we have a system requiring a small room or, for very compact apparatus, that can even be simply placed on a table in an office. The choice between those systems cannot be based on absolute and universal technical or scientific arguments, several other aspects like the accessibility, the cost, the number of samples or the complexity of the data treatment must be taken into account for each specific case. Micro-focus apparatus are progressing rapidly (new apparatus offer sub-micronic voxel sizes) and synchrotron facilities are more and more open to industrial applications making the use of those microtomography setups complementary rather than contradictory.

Nevertheless, it is unquestionable that synchrotron gives 3D images of a better quality (better signal-to-noise ratio) than micro focus apparatus. For instance, Peyrin et al. (1998) calculated, for the same bone sample, a ratio of 70.8 on an ESRF image and 5.8 on a laboratory tomograph image. There are two main reasons for that:

- The X-ray beam produced by the synchrotron is parallel permitting an exact reconstruction by inversion of Radon's transform (the beam is conical for a micro focus source and the reconstruction is inexact out of the symmetry plane of the beam/detector system).

- The X-ray beam produced by the synchrotron is very intense (brilliance is increased by a factor of $10^{6}$ compared to a classical source) and it is then possible to use only a small monochromatic part of the complete beam spectrum. This minimizes several artefacts (Baruchel et al., 2000) and permits precise quantitative measurements of the density or of the chemical composition. With polychromatic sources only comparative measurements with known references are possible.

Furthermore, the size of the synchrotron facilities generally facilitates the use of high performances equipments (very precise translation and rotation systems, high dynamic acquisition hardware, etc.) compared to more modest laboratory set-ups like micro focus tomographs. Even if those general arguments can be discussed in some cases (polychromatic beam is some times used in high energy synchrotron tomography, synchrotron parallel beam is focused to create a virtual point source in some 
nanotomography projects, and a very large signal/noise ratio is not always necessary if binary images are used at the end of the treatments), they correspond to strong advantages for synchrotron compared to micro focus.

Two examples (one for chemical evolution, one for morphological evolution) are presented in this paper to illustrate the possibilities offered by synchrotron microtomography. We are convinced that they would not have been feasible using another source than synchrotron for microtomography.

The number of applications of microtomography in geosciences and in material science is growing very rapidly as proved by the number of specialized sessions proposed in international conferences. General introduction and references can be found in recent review papers and books (Duliu, 1999; Baruchel et al., 2000; Mees et al., 2003).

\section{PRINCIPLES OF SYNCHROTRON X-RAY MICROTOMOGRAPHY}

Consider a homogeneous material characterized by $\mu$, its linear attenuation coefficient, and illuminated by a monochromatic beam of energy $E$, the ratio between $N_{0}$, the number of incident photons, and $N$, the number of photons transmitted through the material thickness $L$ is given by Beer-Lambert's law (Baruchel et al., 2000):

$$
N=N_{0} \cdot \mathrm{e}^{[-\mu L]}
$$

For a heterogeneous material, $\mu L$ must be replaced by the integral of $\mu$ along the photons path. The number of transmitted photon $N$ ' is then:

$$
N^{\prime}=N_{0} \mathrm{e}^{\left(-\int_{\text {path }} \mu(l) d l\right)}
$$

By measuring $N_{0}$ and $N^{\prime}$ the above integral of $\mu$ can be calculated:

$$
\ln \frac{N_{0}}{N^{\prime}}=\int_{\text {path }} \mu(l) d l
$$

Let us now consider an object characterised by its 3D mapping $\mu(x, y, z)$. We place it (Fig. 1) on a rotation table ( $\mathrm{z}$ is the rotation axis) in the X-ray beam (direction $v$ ) and before the 2D detector (plane $(u, z)$, with u perpendicular to $v$ ). Each section perpendicular to $z$ can be considered individually because the synchrotron beam is parallel. For an angular position $\theta$ of the object, $N$ ' can be measured at each point $u$ on the detector and relation (4) can be used to calculate the projection $P$ :

$$
\begin{aligned}
P(\theta) & =\{P(u, \theta) ; u= \pm r\} \\
& =\left\{\ln \left(\frac{N_{0}(u)}{N^{\prime}(u)}\right)=\int_{\text {Ray } u} \mu(v) d v ; u= \pm r\right\}
\end{aligned}
$$

where $(-r)$ and $(+r)$ represent the limits of $u$ on the detector, and Ray $u$ the line parallel to $v$ hitting the detector at $u$. The set of projections $P(\theta)$ for $\theta$ varying between $0^{\circ}$ and $180^{\circ}$ is Radon's transform of $\mu(x, y)$. In 1917, Radon proved mathematically that it is possible to invert this transform and thus it is possible to reconstruct the 3D-map of $\mu$ from a set of projections (Herman, 1980; Natterer, 1999).

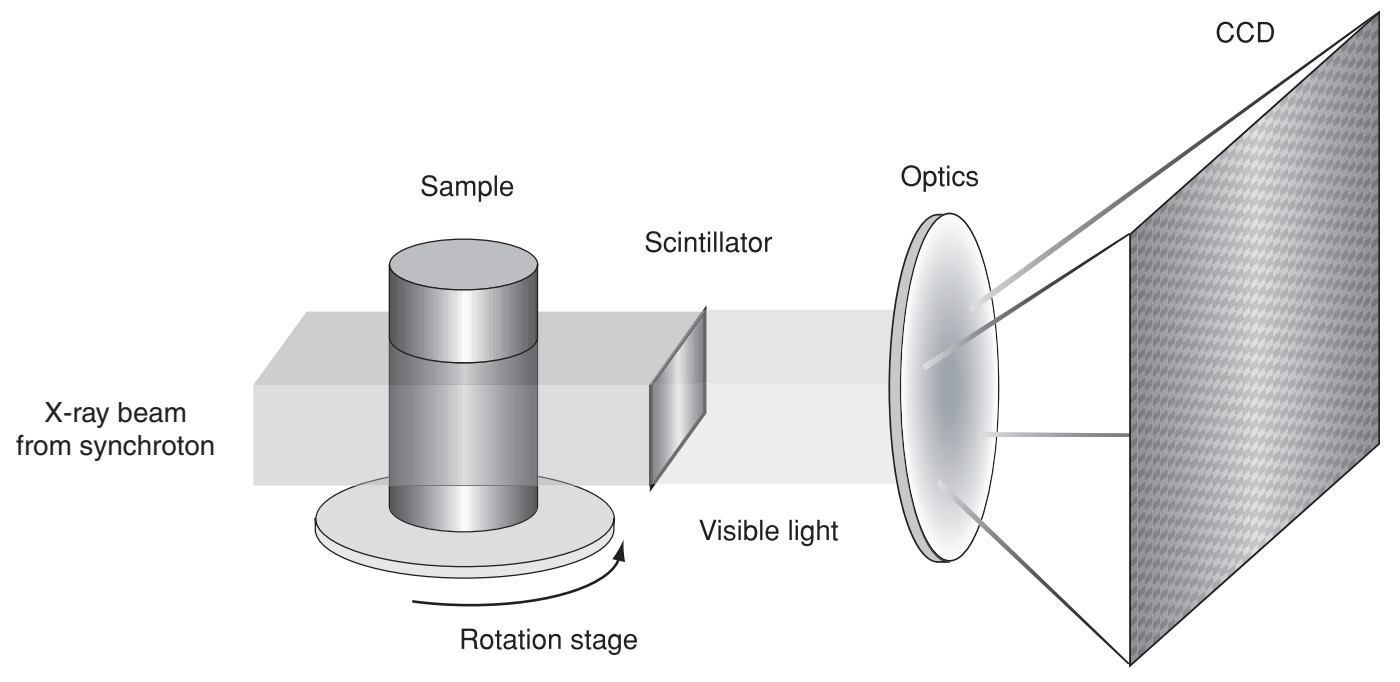

Figure 1

Diagram of the experimental set-up for microtomography. The 3D microstructure of the sample can be reconstructed from the series of projections recorded on the CCD device as the sample is rotated step by step through $180^{\circ}$. 
From the calculated 3D-map of the linear attenuation coefficient $\mu\left[\mathrm{cm}^{-1}\right]$ it is possible to obtain a 3D image of the material thanks to the fact that, for a pure material, the mass attenuation coefficient $\mu / \rho$ is correlated to the photon energy $\mathrm{E}$ and to the atomic number $Z$ : for energies lower than $200 \mathrm{keV}$, the following relation can be used:

$$
\frac{\mu}{\rho}=K \frac{Z^{4}}{E^{3}} .
$$

where $\rho$ is the material density $\left[\mathrm{g} / \mathrm{cm}^{3}\right]$ and $K$ a constant. Equation (5) implies that at a given energy $E$ (an adjustable parameter in synchrotron tomography), the linear attenuation coefficient $\mu$ is proportional to $\rho$ and $Z^{4}$.

The mass attenuation coefficient $\mu / \rho$ of an heterogeneous material containing $i$ elements (mass concentration $w_{i}$ with specific mass attenuation coefficient $\left.(\mu / \rho)_{i}\right)$ is obtained with the following relation:

$$
\frac{\mu}{\rho}=\sum w_{i}(\mu / \rho)_{i}
$$

X-ray computed microtomography consists then in detecting the residual energy of a beam that passes through a sample (this is a radioscopy giving $N^{\prime}$ ) for a large number of different angles (between 900 and 1500 between $0^{\circ}$ and $180^{\circ}$ ). Some reference images are also recorded to control the noise and the homogeneity of the incident beam (this gives $N_{0}$ ). The 3D representation of the X-ray absorption by the sample is then numerically reconstructed from all these 2D images. The most commonly used algorithm for reconstruction is the filtered back-projection method (Baruchel et al., 2000).

The data presented in this paper have been obtained on the ID 19 beam line at the European Synchrotron Radiation Facility (ESRF) in Grenoble. The tomographic set-ups available on ID19 permits the acquisition of $1024 \times 1024$ or $2028 \times 2048$ pixels radiographs with pixel sizes ranging from $40 \mu \mathrm{m}$ to $0.3 \mu \mathrm{m}$. The selected optical set-up placed after the scintillator that converts, as efficiently as possible, X-rays to visible light determines this pixel size. Those parameters also constrain the size of the sample. Indeed, in classical tomography, samples must have a maximal lateral dimension such as the entire projections match the field of view of the digital camera. The maximal dimension is then equal to the pixel size multiplied by the number of pixels comprised on a row of the detector.

At a given energy, absorption of X-rays is function of several physical parameters, mainly the local density and the atomic number of the crossed material. In a porous material, if all the components of the solid phase have about the same $\mathrm{X}$-ray absorption, the 3D-image of the absorption can be transformed into a 3D-image of the porosity. The use of microtomography in material science thus requires that the studied material presents differences of internal absorption, which can be measured within the studied volume elements (voxel). This technique is thus well adapted to multimaterials or porous materials that evolve according to external conditions; examples are glass sintering (Bernard $e t$ al., 2005a), pressure solution in rocks (Renard et al., 2004), dissolution by reactive percolation (Noiriel et al., 2004), mortar leaching (Burlion et al., 2005), transport in semi-solid alloys (Bernard et al., 2005b) or composites damage evolution (Babout et al., 2001).

\section{SOLID-SOLID PHASE CHANGE DURING SINTERING}

Sintering is a process that leads to consolidation of a powder through particle bonding and porosity elimination at temperatures lower than the material melting point. During this heat treatment various phenomena take place like mass transfers, minimising surface energies and inducing large micro structural changes (leading to densification and grain growth), but also phase changes (solid-liquid, solid-gas or solid-solid). In this paragraph we revisit an experiment (Gendron, 2001; Bernard et al., 2001; Bordere et al., 2004; Bernard et al., 2005a) where such a solid-solid phase change have been put into evidence by synchrotron microtomography.

\subsection{Experimental Procedure}

In the work presented by Bernard et al. (2005a), sintering mechanism understanding was the main objective and one of the most important selection criteria was the availability of the materials under the form of regular grains with a size range (between 100 and $300 \mu \mathrm{m}$ ) allowing to image a significant number of grains while a high voxel resolution was kept. Two materials were studied; a commercial sodalime glass powder heat treated at $700^{\circ} \mathrm{C}$ (Gendron, 2001; Bernard et al., 2005a) and a crystallised lithium borate powder heat treated at $720^{\circ} \mathrm{C}$.

Only the case of lithium borate is considered here. Preparation of highly crystallised spherical particles fitting the desired diameters distribution was not straightforward and is detailed in Gendron (2001). The resulting material has been examined by $\mathrm{X}$-rays diffraction to check its crystallised state and it has been verified, with the precision given by $\mathrm{X}$-rays diffraction, that its formula corresponded to $\mathrm{Li}_{6} \mathrm{Gd}\left(\mathrm{BO}_{3}\right)_{3}$.

From the powder, samples were prepared at ICMCB using the following protocol:

- The powder was compacted under uniaxial pressure (1.5 MPa) to form cylinders $(3 \mathrm{~mm}$ in diameter and $5 \mathrm{~mm}$ in height). Polyvinylalcool (PVA, $1 \mathrm{wt} \%$ ) was used as a binder to promote mechanical strength in the green state.

- A first heat treatment, at $650^{\circ} \mathrm{C}$ for $1 \mathrm{~h}$, was done to burn out the PVA $\left(2.5^{\circ} \mathrm{C} \cdot \mathrm{min}^{-1}\right.$ heating rate). 
- A pre-sintering, at $720^{\circ} \mathrm{C}$ during 10 minutes, was realised to be sure that the samples could be manipulated. This sintering temperature was chosen to allow sintering phenomena to take place with a limited evaporation of lithium borate (a weight loss of 7\% was observed after a 1 hour heat treatment at $720^{\circ} \mathrm{C}$ ). These samples were very poorly densified and constituted the starting point to study the microstructure evolution.

The consecutive isothermal sintering treatments and microtomography measurements were sequentially performed on the pre-sintered samples at ESRF on the ID19 imaging and diffraction beam line. Sintering steps were done by introducing directly the sample in a furnace hold at $720^{\circ} \mathrm{C}$. The X-ray beam energy was set to $17.5 \mathrm{keV}$, which was adapted to the nature and the thickness of the material. A typical experiment consisted in recording 900 projection images and about 100 reference images for flat field correction using the $2048 \times 2048$ pixels Frelon CCD camera with a pixel size of $4.91 \mu \mathrm{m}$.
XRD of the powder obtained from the final material (after the maximum sintering time of $190 \mathrm{~min}$.) only revealed $\mathrm{Li}_{6} \mathrm{Gd}\left(\mathrm{BO}_{3}\right)_{3}$ phase. However, the observed weight loss as well as the modification of the grains surface appearance suggested that the mechanisms involved in this experiment were not as simple as expected.

\subsection{Results}

The first results concern the visualisation of $2 \mathrm{D}$ sections through the scanned volume of the sample. Six images of sections chosen at approximately the same height within the sample illustrate the material evolution as a function of the sintering time (Fig. 2). These images are only $2 \mathrm{D}$ views. However, they concern the same sample and the same area, and as such they provide interesting and original insights on the changes associated to sintering.

In the case of glass powder samples, it was shown (Bernard et al., 2001; German, 1996) that the sections clearly

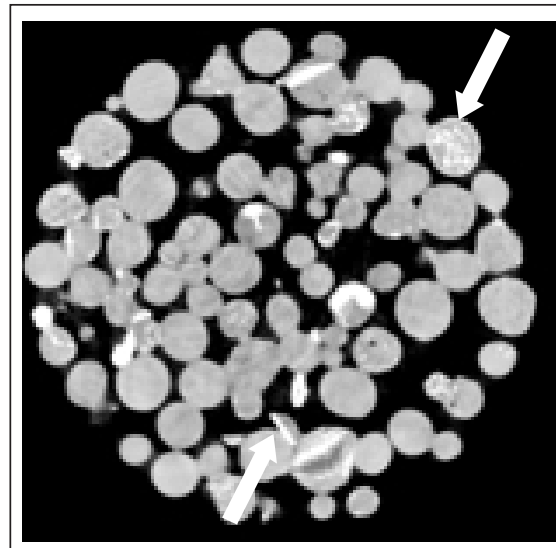

$\mathrm{T}=5 \mathrm{~min}$, section $301(\phi=37.5 \%)$

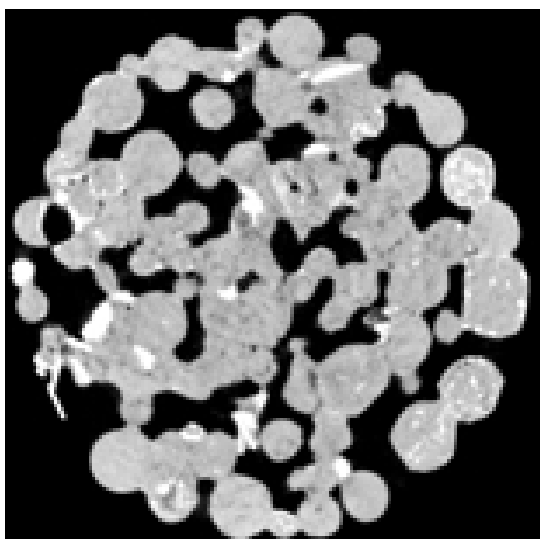

$T=100 \mathrm{~min}$, section $290(\phi=30.1 \%)$

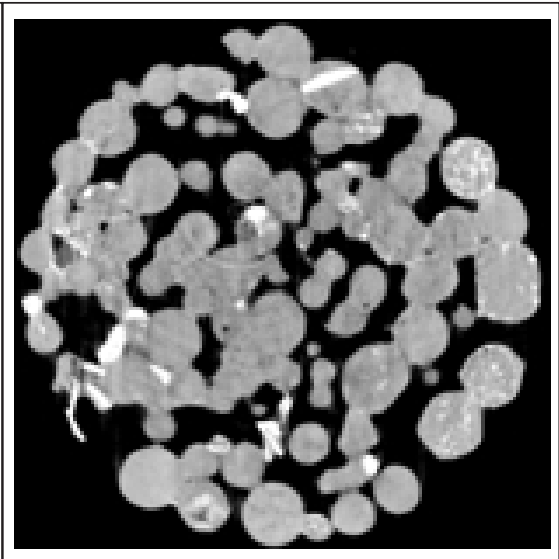

$\mathrm{T}=35 \mathrm{~min}$, section $294(\phi=31.9 \%)$

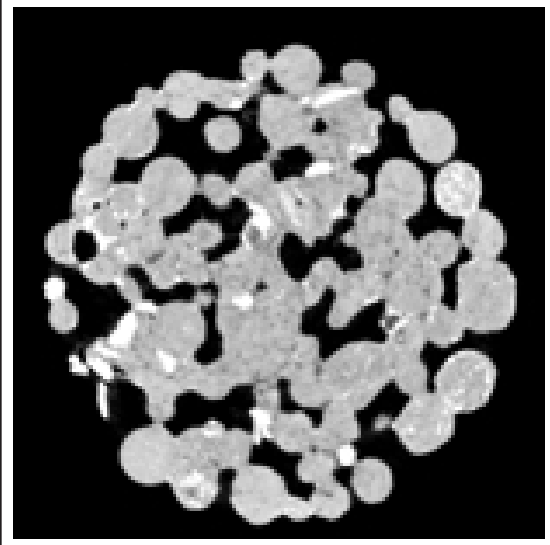

$\mathrm{T}=140$ min, section $291(\phi=28.2 \%)$

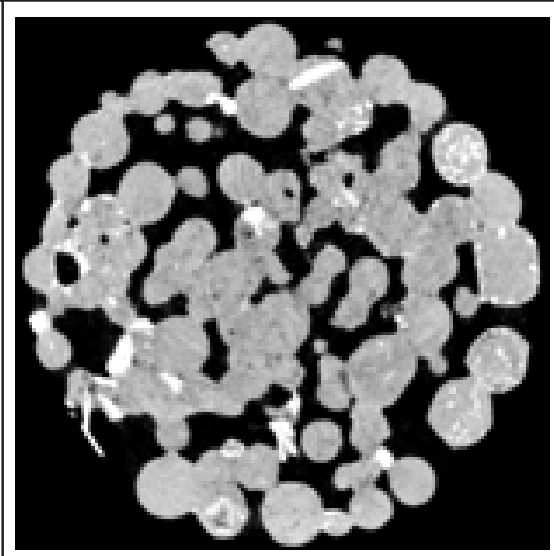

$\mathrm{T}=70 \mathrm{~min}$, section $290(\phi=31.1 \%)$

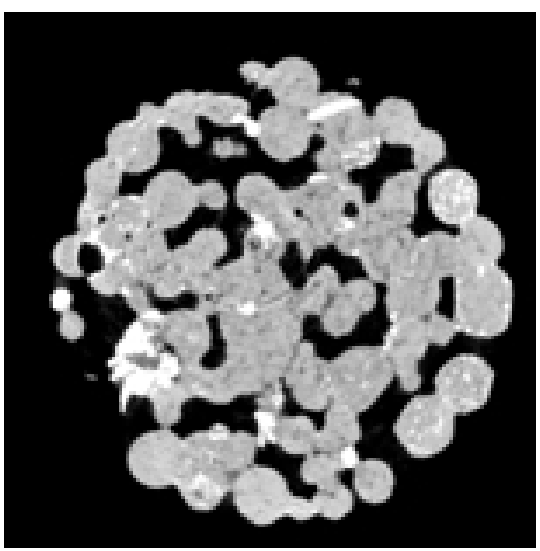

$\mathrm{T}=190 \mathrm{~min}$, section $286(\phi=28.1 \%)$

Figure 2

Sections approximately at the same height through the lithium borate sample during sintering. A limited densification occurred and an absorbing unknown phase (in white) is visible in the form of platelets or crystallites (arrows). 
illustrate the 3 classical stages of sintering; Necks growth, grains growth and porosity elimination. The evolution illustrated here differs greatly from this although the initial states of the two materials are quite similar: porosity is about the same (36\%), grains present rather regular forms and few contacts between them are initially present.

For short sintering times, $t_{s}=5$ min, grain sections appear as very regular. Grain arrangement remains close to the initial configuration that corresponds to a dense random packing of spherical particles. Very few defects, like broken grains due to the compression, are present in the system. For that short sintering time, the densification process is only starting and the section only reveals a few necks between particles. The major astonishment at this stage was the presence of a small proportion (about $1.5 \%$ of the volume initially) of heterogeneities within the grains (lithium borate in grey on Figure 2, heterogeneities in white). This parasitic phase appeared in white (material more opaque to $\mathrm{x}$-rays) either in the form of crystallites or in the form of platelets (arrows on Figure 2). It is very likely that those heterogeneities appeared during the preparation of the lithium borate powder by demixing in the liquid state. Our objective in this paper is not to elucidate the origin and the nature of this unknown phase but only to show that by synchrotron CMT it possible to precisely quantify the evolution of the volume fractions of the different solid phases present in the sample. It should be noted however that this second phase can influence the sintering process.

During sintering, a limited densification occurred (Fig. 3) and the volume fraction of the unknown phase slightly increased (Fig. 4). Necks that appeared at the contacts between grains present specific configuration (Figs 2 and 5, in the white squares). Such morphology is usually associated with the initial stage of a liquid-phase sintering (German, 1996). The presence of a liquid phase generally facilitates the densification, but if another mechanism, like evaporation/ condensation, is also operative, this can strongly limit the final density. As a matter of fact, the modification of the aspects of the grains surface (Figs 2 and 5) and the weight loss noticed along the heat treatment (about $7 \%$ per hour at $720^{\circ} \mathrm{C}$ ) corresponded likely to an evaporation/condensation mechanism. All these different arguments are in favour of a combination of mechanisms.

Very few quantitative and relevant morphological measurements (number of contacts or neck size for example) can be obtained from such 2D images. It is not the case in 3D. Three small volumes $\left(1.5 \times 1.5 \times 1.2 \mathrm{~mm}^{3}\right)$ have been extracted from the complete data sets (Fig.5). After registration they offer 3D images of the surface of the samples and permit precise computation of the evolutions of the local porosity (Fig. 3) and of the volume fraction occupied by the unknown phase (Fig.4). Volumetric estimates of those volume fractions can be performed with a precision (about $0.5 \%$ ) much better than the one obtained on 2D sections (Fig. 3).

Using smaller $3 \mathrm{D}$ images $\left(0.5 \times 0.5 \times 0.5 \mathrm{~mm}^{3}\right)$ the way the absorbing phase is distributed between platelets and crystallites can be estimated (Fig. 6) as well as its evolution with time within a single grain; increase is mainly due to crystallites. The geometrical evolution of a single platelet (Fig. 7) can also be evaluated: table 1 gives an estimation of the evolutions of the dimensions $(\mathrm{a}=$ small radius, $\mathrm{b}=$ large radius, $\mathrm{c}=$ thickness), the surface $(\mathrm{S})$ and the volume $(\mathrm{V})$ of the individualized platelet.

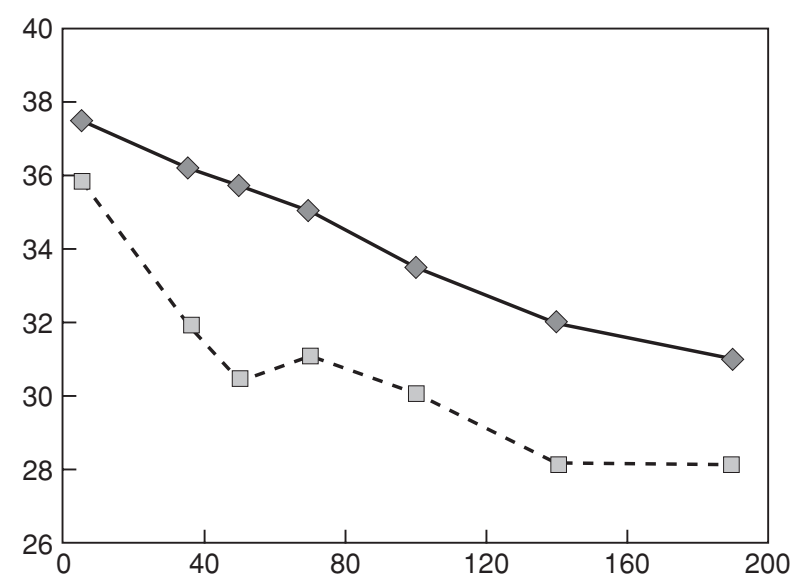

Figure 3

Evolution of porosity (\%) with sintering time (min) estimated on sections (--) and on partial volumes (-) of the lithium borate sample.

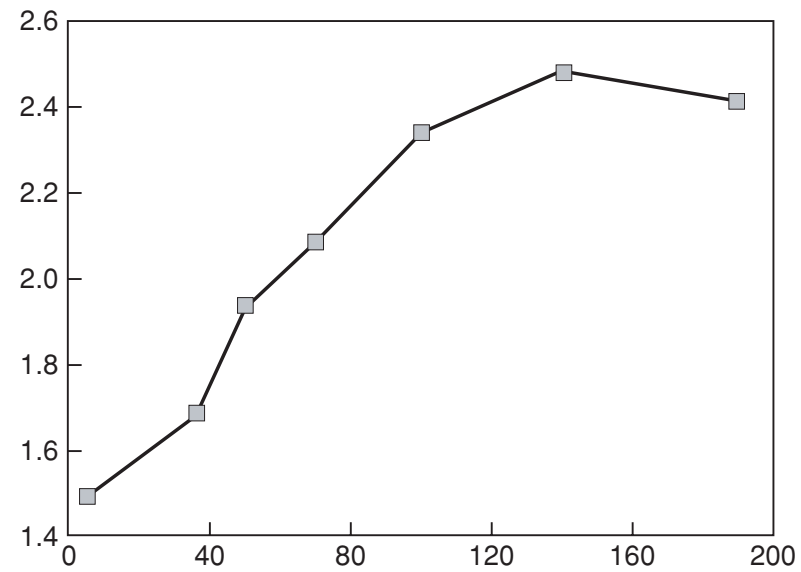

Figure 4

Evolution of the volume fraction (\%) of the unknown dense phase with sintering time (min). 


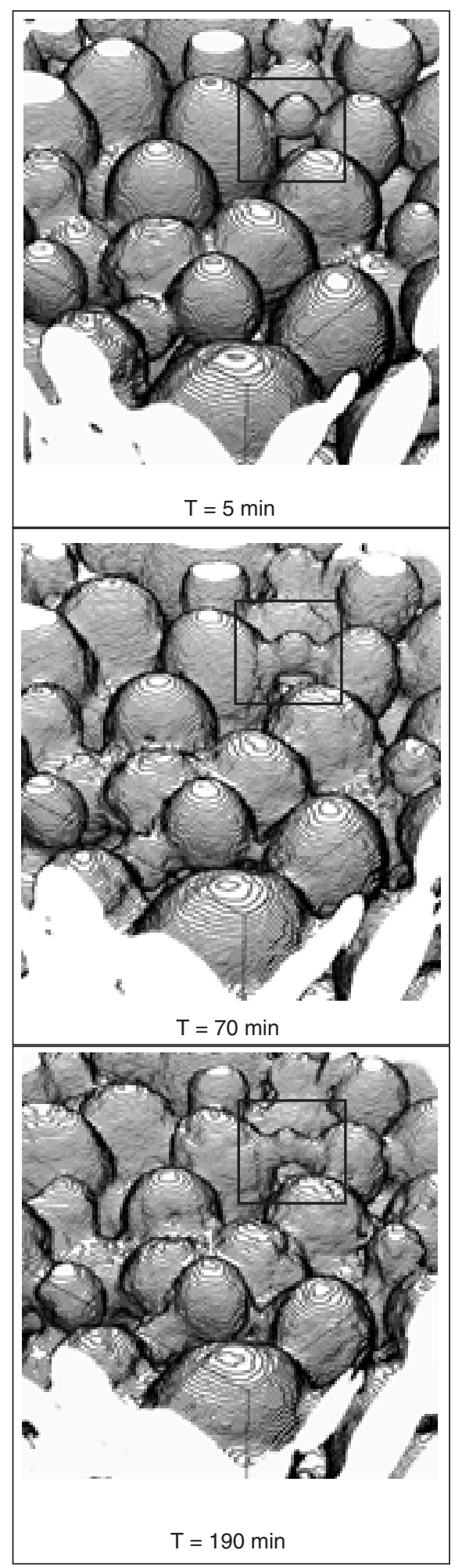

Figure 5

$3 \mathrm{D}$ visualisation of the same region near the top of the lithium borate sample for three different sintering times. The squares pointed on grains where morphological changes are spectacular.

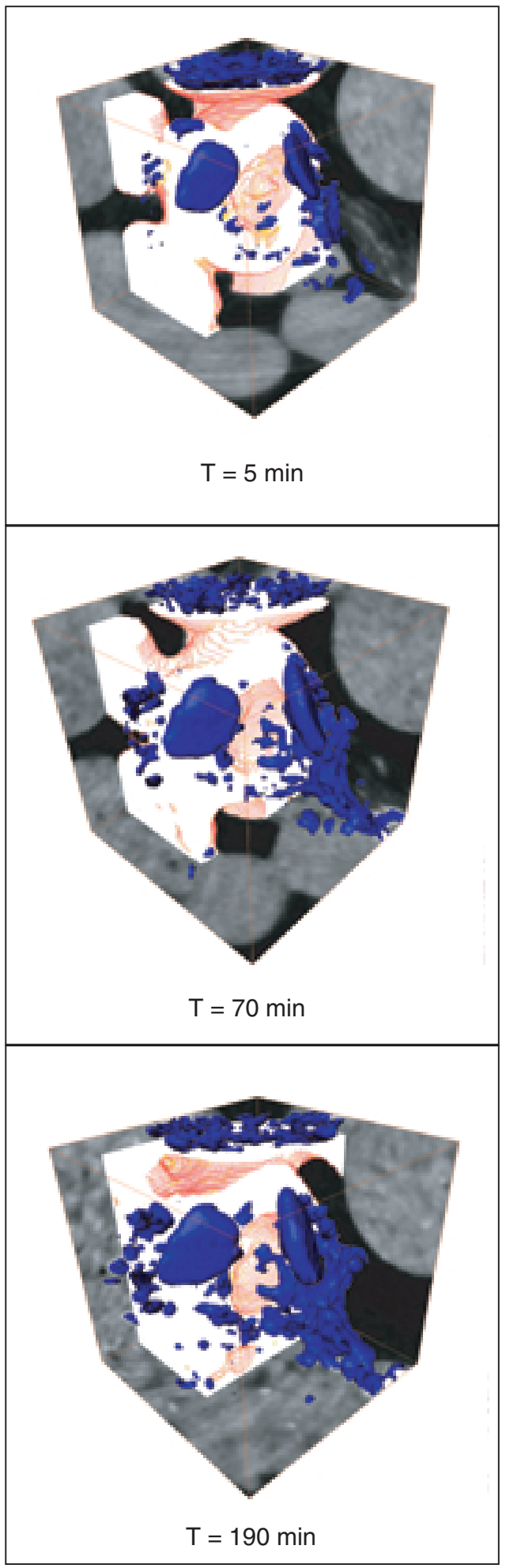

Figure 6

Morphological evolutions of the absorbing unknown phase (in blue) within of a single grain (in red). Platelets slightly increase as well as the number of crystallites. 


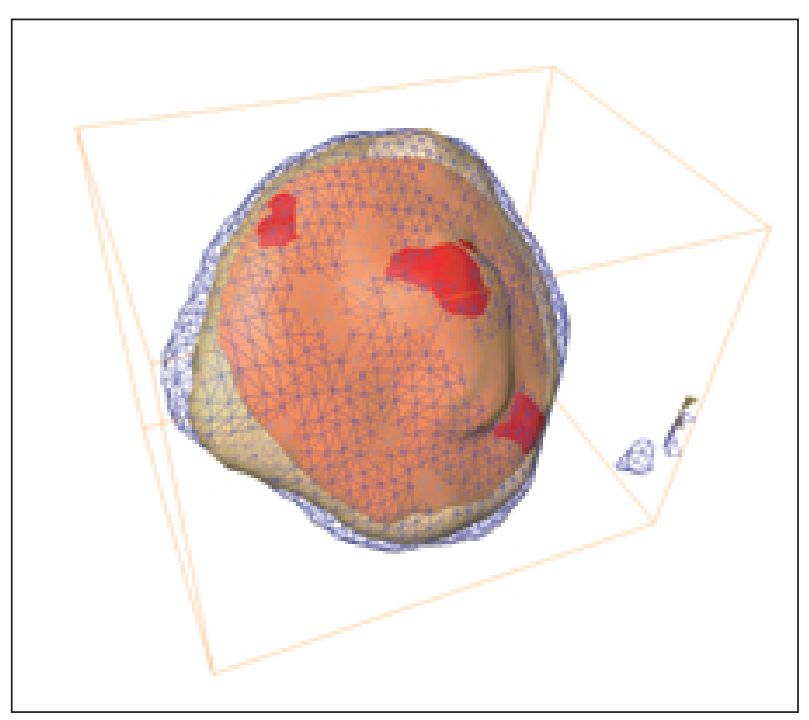

Figure 7

Superposition of three images of the same platelet of the absorbing solid phase at three different sintering times (5 min, $70 \mathrm{~min}$ et $190 \mathrm{~min}$ ). Dimensions are given Table 1.

Synchrotron microtomography appears as a technique providing quantitative $3 \mathrm{D}$ information on the different phases that are present with an unrivalled precision and this, even when the volume fraction of one phase is too small to permit its detection by XRD in the powder obtained from the crystallised material. However, in the present case, synchrotron microtomography would not have been sufficient for a complete understanding of the process, some complementary studies are necessary, for instance to confirm the presence of a liquid phase (direct observation of the sintering of a few grains under a microscope) or to precisely determine the composition of the absorbing phase.

\section{TABLE 1}

Characterisation of the morphological evolution of a single platelet of the absorbing solid phase (Fig. 7)

\begin{tabular}{c|c|c|c|c|c}
\hline $\begin{array}{c}\text { Time } \\
(\min )\end{array}$ & $\begin{array}{c}\mathrm{a} \\
(\mu \mathrm{m})\end{array}$ & $\begin{array}{c}\mathrm{b} \\
(\mu \mathrm{m})\end{array}$ & $\begin{array}{c}\mathrm{c} \\
(\mu \mathrm{m})\end{array}$ & $\begin{array}{c}\mathrm{S} \\
\left(\mu \mathrm{m}^{2}\right)\end{array}$ & $\begin{array}{c}\mathrm{V} \\
\left(\mu \mathrm{m}^{3}\right)\end{array}$ \\
\hline 5 & 117 & 125 & 44 & $2.9710^{4}$ & $2.9610^{5}$ \\
70 & 132 & 144 & 45 & $3.6910^{4}$ & $3.4410^{5}$ \\
190 & 136 & 147 & 50 & $3.9810^{4}$ & $4.1810^{5}$ \\
\hline
\end{tabular}

$\mathrm{a}=$ small radius, $\mathrm{b}=$ large radius, $\mathrm{c}=$ thickness, $\mathrm{S}=$ external surface, and $\mathrm{V}=$ volume

\section{REACTIVE PERCOLATION THROUGH A NATURAL CARBONATE SAMPLE}

In the frame of a national project concerning $\mathrm{CO}_{2}$ sequestration in reservoirs (PICOR), a reactive percolation experiment with carbon dioxide-saturated water was performed on a porous limestone in order to better understand the relationships between fluid chemistry, hydrodynamics and structural properties at the pore and core scales. X-ray microtomography has been used to follow the evolution of the core micro-geometry in details. Preliminary results have been presented elsewhere (Noiriel et al., 2004; Noiriel et al., 2005) and we want here to describe more precisely the way microtomographic data treatments have been conducted. The project is still in progress and improvements in the methods that are necessary will be discussed.

\subsection{Experimental Procedure}

A limestone cylindrical core of $9 \mathrm{~mm}$ diameter and $21 \mathrm{~mm}$ length has been prepared from a rock sample extracted from a quarry in the Lérouville formation (Lérouville, Paris Basin, Meuse). The rock is essentially composed of calcite under the form of large cemented grains and minor fractions (maximum 5\%) of carbonated micritic mould and fragments of altered material containing iron oxides.

The core is placed into a percolation cell after a coating insuring an efficient sealing of its periphery. The core is then saturated with calcite-equilibrated water and $\mathrm{CO}_{2}$-enriched water is injected at constant flow rate. Three different stages of the reactive percolation process have been conducted with three different fluids; Deionised water equilibrated with limestone at atmospheric partial pressure of $\mathrm{CO}_{2}$, deionised water, and $0.010 \mathrm{M} \mathrm{NaCl}$ in deionised water. Inlet fluids, initially degassed, are maintained equilibrated with carbon dioxide at the partial pressure of $0.10 \pm 0.01 \mathrm{MPa}$ during the experiment. Before and after those percolation stages, the sample is removed from the cell and imaged by X-Ray microtomography. Precise description of the experiment can be found in Noiriel et al. (2004 and 2005), here we will only consider the treatments necessary to quantitatively characterize the four 3D images obtained from microtomographic acquisitions: initial state, state 1 (after the first percolation stage, $1 \mathrm{~h} 24 \mathrm{~min}$ ), state 2 (after the second percolation stage, $12 \mathrm{~h} 30 \mathrm{~min}$ ), and state 3 (after the third percolation stage, 8 h 30 min).

Microtomographic acquisitions have been performed at the ID19 beam line of the European Synchrotron Radiation Facility (ESRF, Grenoble, France) at energy of $35 \mathrm{keV}$ using the $2048 \times 2048$ pixels FReLoN camera. For each scan 1200 radiographies were acquired with a pixel size of $4.91 \mathrm{~mm}$.

After reconstruction by filtered retro-projection we obtained four images of the $\mu$ volumetric distribution in the part of the sample close to the fluid injection side of the core (at about $1 \mathrm{~mm}$ from the inlet surface). Those data sets are coded on 32 bits real numbers and they are converted into greyscale $3 \mathrm{D}$ images ( 0 to 255 ) coded on one byte ( 8 bits). By convention, dark voxels correspond to low X-ray 
attenuation (voids), whereas light voxels denote high X-ray attenuation (matrix).

\subsection{Results}

Results presented here correspond to the four volumes $\mathrm{V}_{0}$, $\mathrm{V}_{1}, \mathrm{~V}_{2}$ and $\mathrm{V}_{3}$ linked to the initial state and states 1 to 3 . All sections comprise about $2000 \times 2000$ pixels and the number of sections varies between 1500 and 1800. 1400 of those sections match a common zone of the sample for the four volumes.

\subsubsection{D Results}

The first results are the 2D sections where the different phases can be visually distinguished (Fig. 8). In spite of their high quality those images are quite difficult to segment into the different phases listed above. This problem was left behind because the main segmentation we were interested in was between the solid and the pore, and this one is rather simple. The two sections presented Figure 8 belong obviously to the same region but, because it is impossible to replace with enough precision the core in the same position after a percolation stage, local comparisons are possible (upper left quarters on Figure 8) but not global ones. A global $3 \mathrm{D}$ registration of the volumes (about 6 GBytes each) was necessary. 3D image registration is a complex problem intensively studied in the field of medical imaging (Maintz and Viergever, 1998). If we except the size of the images, the problem seemed to be simpler in our case than in the case of medical images: low noise level, high contrast, existence of numerous sharp features in the microstructure, and furthermore the transformation can be assumed to be a rigid transformation. As a preliminary approach, the simplest one has been tested: examining visually sections of both volume $\left(\mathrm{V}_{0}\right.$ and $\left.\mathrm{V}_{1}\right)$ in near correspondence, a set of landmarks was selected and from their coordinates in both volumes a matrix of transformation was calculated through a least square algorithm. After a few (2 or 3 ) iterations where markers with large difference between measured and predicted positions were eliminated, the final transformation was applied to $V_{1}$. Both volumes being now in the same position on the same grid, computation of the difference was immediate (Fig. 9). The first percolation stage was done with a fluid only slightly unbalanced relatively to the minerals and the expected modifications of the microstructure were very limited. Consequently the difference between two well-registered sections should mostly display noise, as it is apparent on Figure 9. The precision of the registration was of the order of half a voxel and permitted to put into evidence what was observed during the experiment (Noiriel et al., 2005): in the

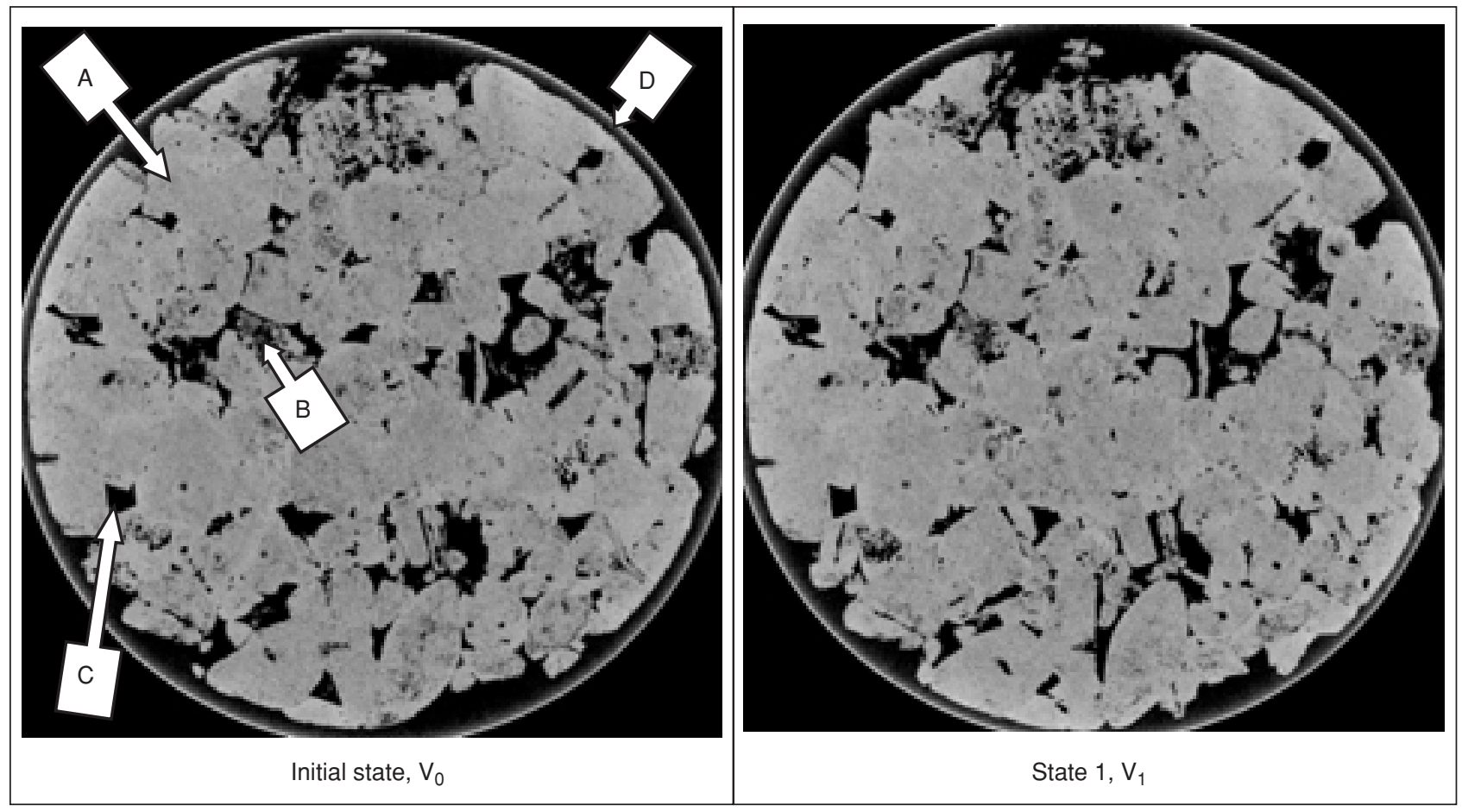

Figure 8

Two sections approximately at the same height through the limestone core in the initial state $\left(\mathrm{V}_{0}\right)$ and after the first percolation stage $\left(\mathrm{V}_{1}\right)$. $\mathrm{A}=$ Large calcite grain, $\mathrm{B}=$ Micritic mould, $\mathrm{C}=$ Pore, $\mathrm{D}=$ Sealing resin. 
first percolation stage the modified solid phase was mostly the micritic mould that has been dissolved (very high reactive surface) and mobilized under the form of small particles. This is clearly illustrated by the second row of Figure 9.

Exploring the variation along the core axis of the mean of $\mathrm{V}_{0}-\mathrm{V}_{1}$ by section, we rapidly discovered that the extreme values were not associated to the largest modifications but to ring artefacts. Because the $3 \mathrm{D}$ reconstruction from the projections implies a transformation from a cylindrical system of coordinates $(\mathrm{u}, \theta, \mathrm{z})$ to a Cartesian one $(\mathrm{x}, \mathrm{y}, \mathrm{z})$, the noise affecting the sections of the reconstructed volume generally presents marked circular patterns. Ring artefacts are extreme manifestations of those patterns. Those artefacts (Fig. 10) are usually attributed to a non-linear behaviour of some pixels of the detector during acquisition. Being linked to the detector and not to the sample, they distinctly alter the difference between the volumes.
Ring artefacts are recurrent in high-resolution microtomography but their systematic correction is still a problem. Disregarding the correction directly on the 3D images (always partly manual) we developed a filter to be applied before reconstruction. The origin of the filter is the classical observation that a large ring artefact is always associated to a linear mark in the corresponding sinogram (representation of the microtomographic data in the plane $(\mathrm{u}, \theta)$ for a given section). Smoothing this linear mark can then eliminate the ring artefact. This filter and the various control parameters we have introduced, for instance to eliminate partial rings without perturbating the rest of the image (Fig. 10), are described in Bernard and Chirazi (2005).

Ring artefacts correction has been very effective in our case (Fig. 11) and we tried to register the corrected volumes in the way we followed previously for volumes $\mathrm{V}_{0}$ and $\mathrm{V}_{1}$. There we encountered difficulties to find, with the required
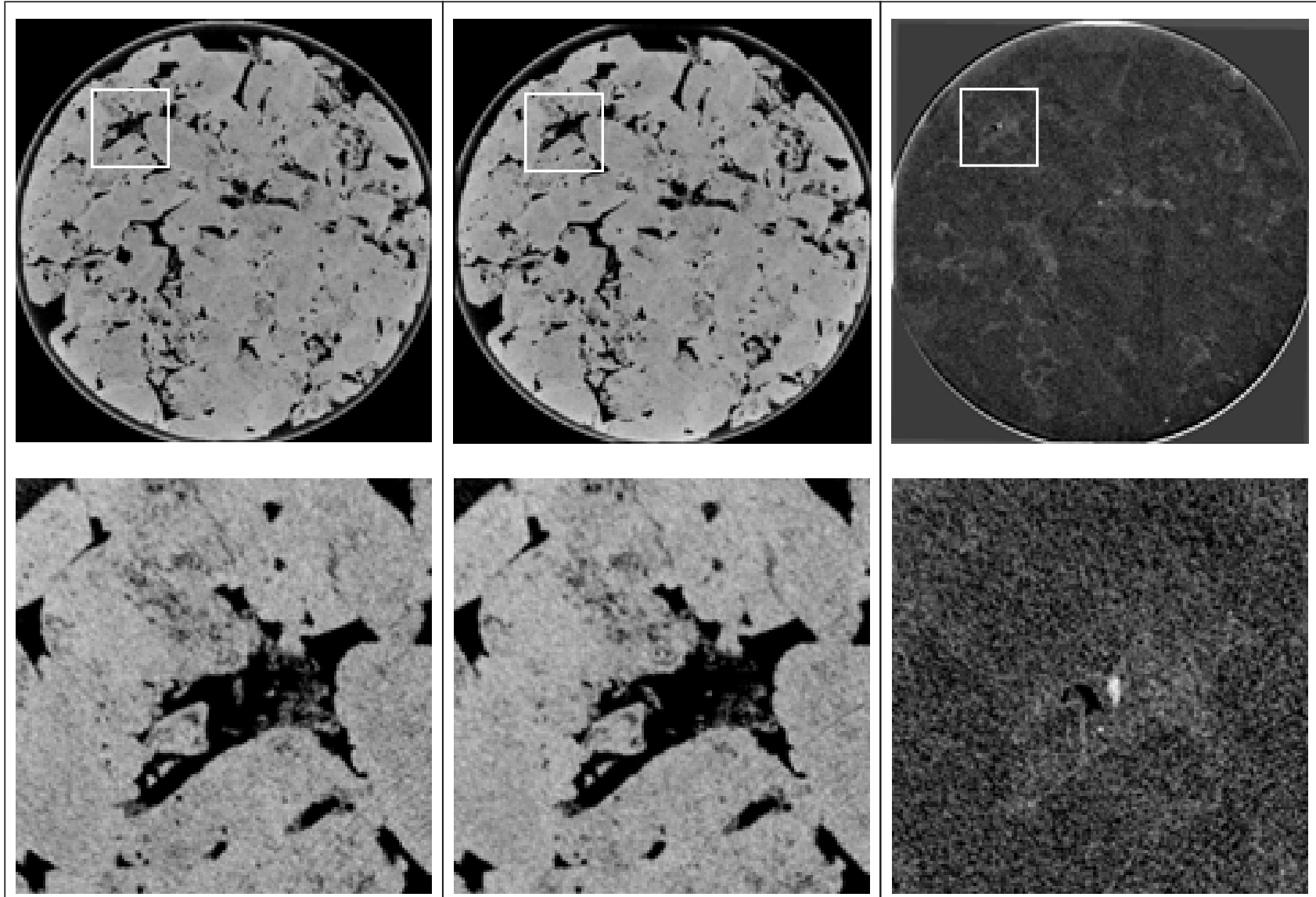

Volume $\mathrm{V}_{0}$

Volume $\mathrm{V}_{1}$

Volume $\left(\mathrm{V}_{0}-\mathrm{V}_{1}\right)$

Figure 9

From left to right; two sections at the same position (after $3 \mathrm{D}$ registration of $\mathrm{V}_{1}$ on $\mathrm{V}_{0}$ ) at the initial state and after the first percolation stage, difference between both images. The enlarged images of the second line show how the difference permits the characterisation of the particles displacement during the first percolation stage. 


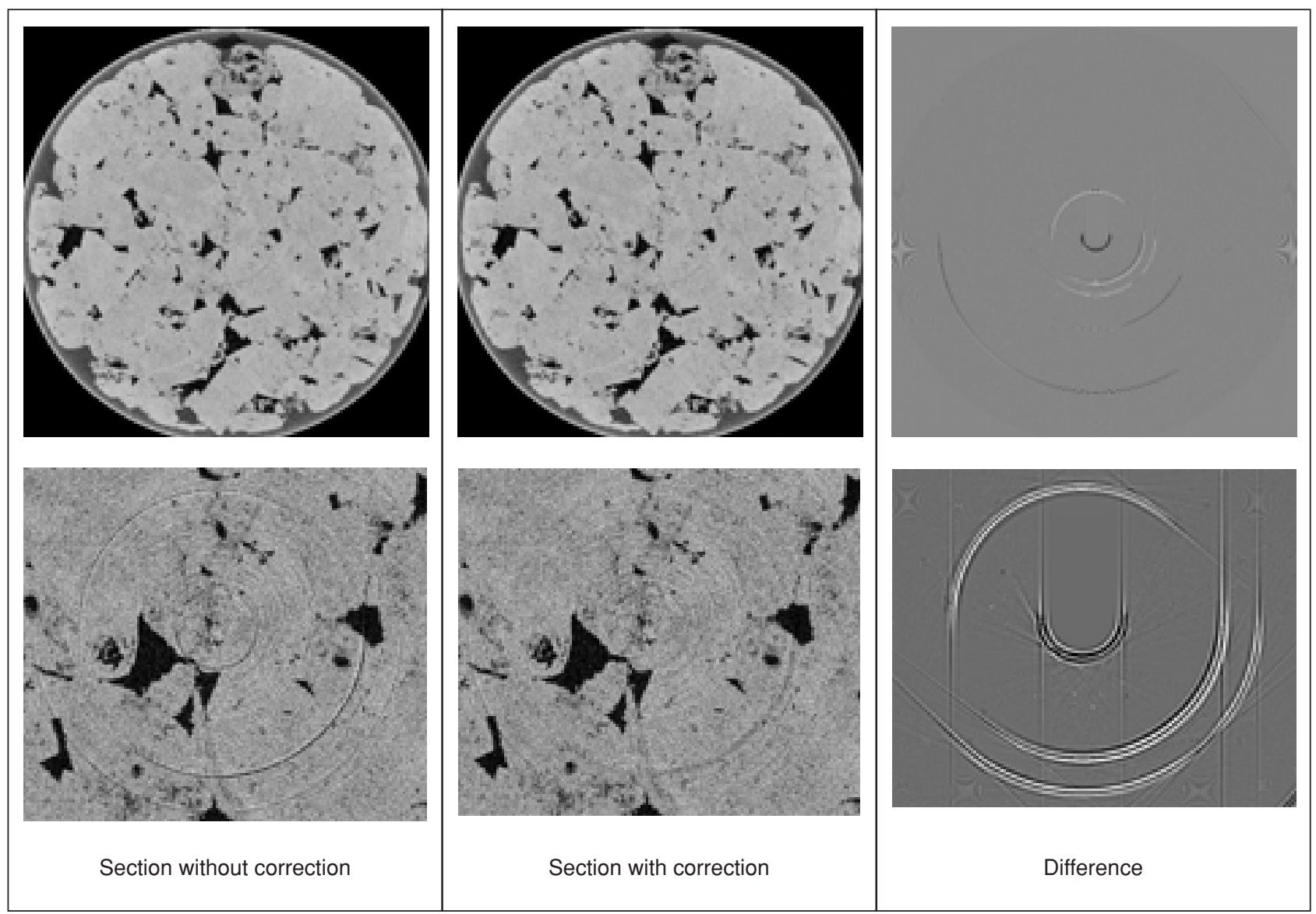

Figure 10

Left to centre; complete views (upper line) and enlarged central views (lower line) of a section before and after correction of the ring artefacts. The difference between those images (right) shows that the filter permits the correction of incomplete rings. Filter parameters have been selected to modify the image only where it is relevant, i.e. where the pore shapes are affected.

precision, the necessary landmarks and, consequently, to determine the global rigid transformation. The simple approach used for the first registration appeared as too sensitive to the quality of the $3 \mathrm{D}$ images $\left(\mathrm{V}_{0}\right.$ and $\mathrm{V}_{1}$ have been acquired the same day in exactly the same conditions, $\mathrm{V}_{3}$ have been acquired some months after in slightly different conditions). New algorithms are under evaluation for the registration of the complete volumes. Because smaller volumes can be manipulated interactively with a computer equipped by a good graphic card, the registration module available in the software Amira (Mercury Computer Systems) have been used for "small" volumes $(400 \times 400$ $\times 400$ voxels corresponding to a large pore).

\subsubsection{D Results}

Four volumes, $\omega_{0}$ to $\omega_{3}$, extracted respectively from $\mathrm{V}_{0}$ to $\mathrm{V}_{3}$ have been registered, partly automatically and partly manually, with a precision high enough to permit the visualisation presented Figure 12 of the movements of the fluid/solid interface: on a grey scale image of a section at the initial state, lines indicating the position of the fluid/solid interface at states 1 to $3\left(I_{1}\right.$ to $I_{3}$ ) are drawn. As on Figure 9, particle movements during the first percolation stage are visible (A and B on Figure 12). In addition dissolution of the large grains, that was only effective during the second and third stages of percolation, is visualized.

To quantitatively characterise the evolution of the sample, differences between the volumes $\omega_{0}$ to $\omega_{3}$ can be computed as done between $\mathrm{V}_{0}$ and $\mathrm{V}_{1}$ (Fig. 9). Each difference consists in a grey level (0-255) volume and the utilization of this series of volumes appears to be quite complicated. The simplification came from the following idea: for a given position in the four registered volumes we have the four states of the same voxel at the four scanning times. If we only distinguish between two situations for a voxel; being in the pore (0) or being in the solid (1), a bit is sufficient to represent the state of a voxel at a given time. In a grey level 3D image, eight bits are available for each voxel, two times 

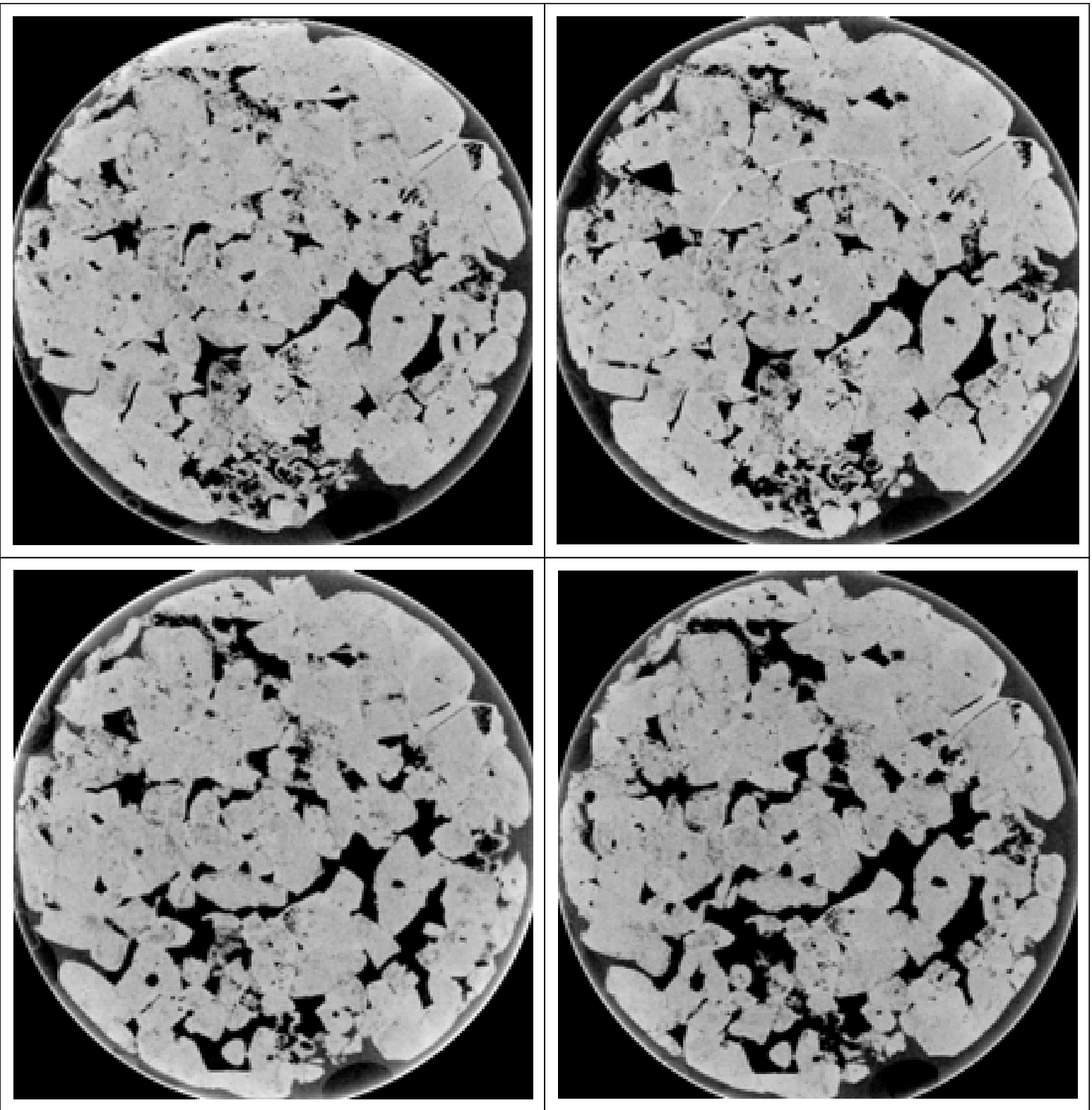

Figure 11

Four sections corrected of the ring artefacts and approximately at the same height through the limestone core in the initial state $\left(\mathrm{V}_{0}\right)$ and after the different percolation stages $\left(\mathrm{V}_{1}, \mathrm{~V}_{2}, \mathrm{~V}_{3}\right)$.

what is needed in our case to resume on a single 3D image the complete history of the studied volume. A new volume is then built in the subsequent way: for each voxel:

- If it was in solid in the initial state, the bit number 5 is set to one. In the contrary, it is set to zero.

- If it was in solid in the state 1 , the bit number 6 is set to one. In the contrary, it is set to zero.

- The same rule is applied for states 2 and 3 to fix the bits 7 and 8.

- The four remaining bits are set to zero.
Each voxel of the ensuing volume $\mathrm{H}$ has a value that is a digest of the evolution of the voxel during the percolation experiment. Each of the 16 possible values can be simply decoded: for instance, 112 corresponds to the binary code 00001110 meaning that the voxel was in the solid and has been dissolved during the third percolation stage. Among the 16 possible values, 6 are representing $99.4 \%$ of the volume $H$ $(0,16,32,48,112$, and 240). They correspond to the most logical scenarios for a voxel during the percolation experiment (Table 2). 


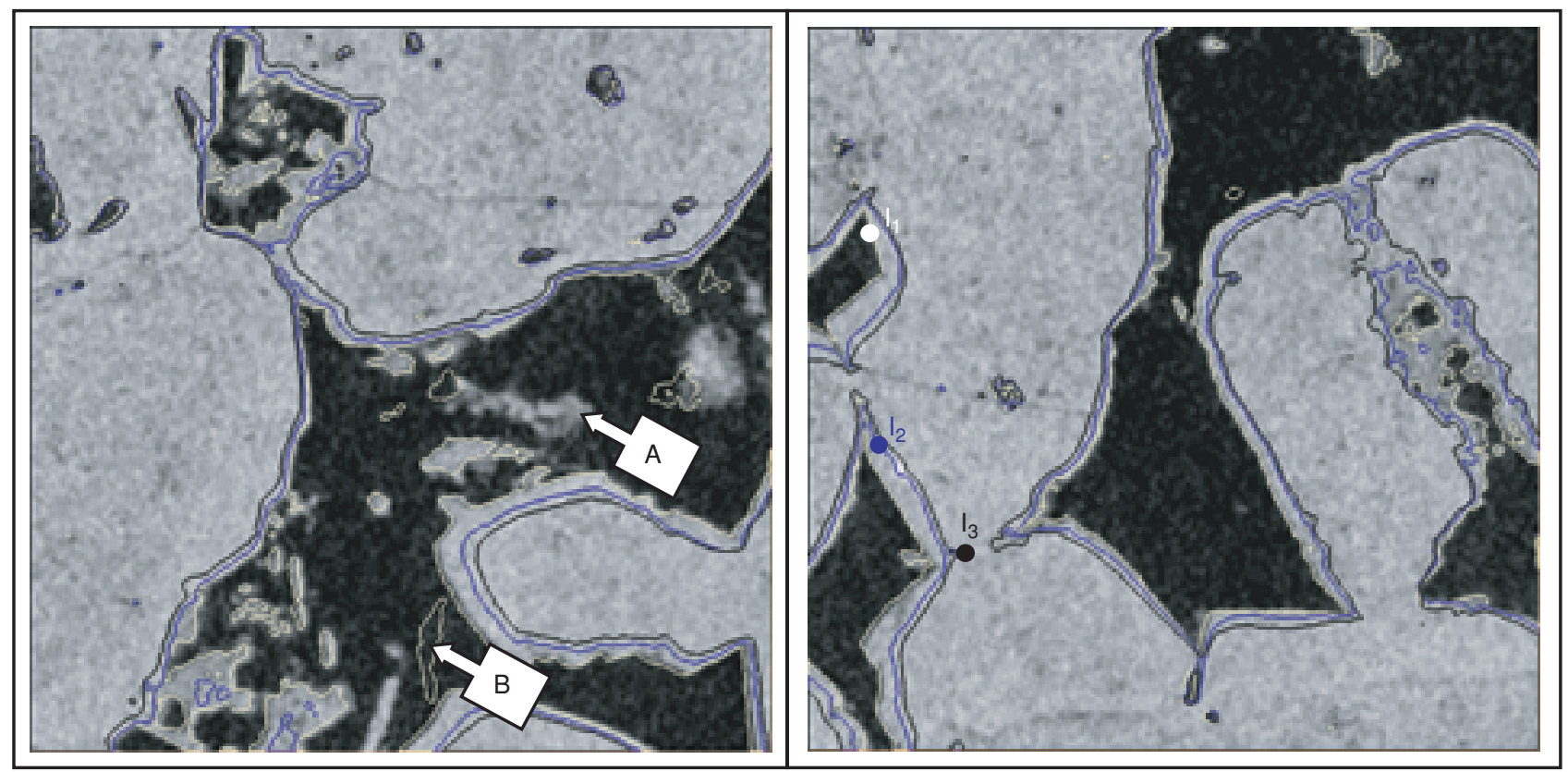

Figure 12

Two sections through the small volume $\omega_{0}$ (in grey scale) on which are superimposed the locations of the fluid/solid interface after the three percolation stages (marked $\mathrm{I}_{1}, \mathrm{I}_{2}, \mathrm{I}_{3}$ on the right view). A particle of the micritic mould that disappeared during the first percolation (by dissolution or displacement) is pointed in $\mathrm{A}$ and a particle that appeared during the same time is pointed in $\mathrm{B}$.

\section{TABLE 2}

Description of the six most important scenarios followed by the voxels during the reactive percolation stages

(moving particles correspond to number 32)

\begin{tabular}{c|c|c}
\hline Value & $\%$ & \multicolumn{1}{c}{ Scenario } \\
\hline 0 & 26.5 & $\begin{array}{l}\text { Voxels in the pore for } \omega_{0} \text { to } \omega_{3} \\
\text { Voxels in the solid for } \omega_{0} \text { and dissolved or } \\
\text { displaced during the first percolation stage } \\
\text { Voxels in the pore for } \omega_{0}, \text { in the solid for } \omega_{1}, \\
\text { and in the pore afterwards. }\end{array}$ \\
48 & 16.1 & $\begin{array}{l}\text { Voxels in the solid for } \omega_{0} \text { to } \omega_{1} \text { and dissolved } \\
\text { during the second percolation stage } \\
\text { Voxels in the solid for } \omega_{0} \text { to } \omega_{2} \text { and dissolved } \\
\text { during the third percolation stage } \\
\text { Voxels in the solid for } \omega_{0} \text { to } \omega_{3}\end{array}$ \\
\hline
\end{tabular}

A new partition of the volume $\mathrm{H}$ in six regions (as a first approximation, the $0.6 \%$ of voxels not associated with a scenario given on Table 2 are artificially distributed between the six regions in function of their value) is build providing 3D visualisation of the pore wall evolution (Fig. 13) and making accessible the computation of the surfaces delineating the six regions. 15 patches were defined in that way and, for a given state, the fluid/solid interface could be calculated combining the appropriate patches. The first results concerning the fluid/solid interface were not surprising (Noiriel et al., 2005): the interface decreases by $5.7 \%$ during the first percolation stage, by $22.2 \%$ during the second, and by $4.5 \%$ during the third. What was more unexpected was the fact that several of those patches were present in the definition of the fluid/solid interface at different states. A patch present in the fluid/solid interface for two consecutive states represents a portion of the potentially reactive surface that has not reacted during the percolation stage (within the precision of the method, including acquisition and treatments). During the first percolation stage $82.1 \%$ of the fluid/solid interface remained unchanged, $18.4 \%$ during the second percolation stage, and $29.8 \%$ during the last one.

With this approach we have produced a direct estimate of the evolution in time of what can be depicted as an effective reactive surface at the pore scale.

\subsubsection{Permeability Computation}

All along the percolation stages the pressure drop has been recorded permitting estimates of permeability at the different states (Noiriel et al., 2005).

From the 3D images of the micro geometry provided by microtomography it is relatively straightforward to define grids that can be directly used to compute transport properties like permeability (Renard et al., 2004; Bernard et al., 2005b). For the complete sample (diameter $=9 \mathrm{~mm}$, length $=21 \mathrm{~mm}$ ) in the initial state (porosity $=15 \%$ ) about $1.710^{9}$ voxels are 


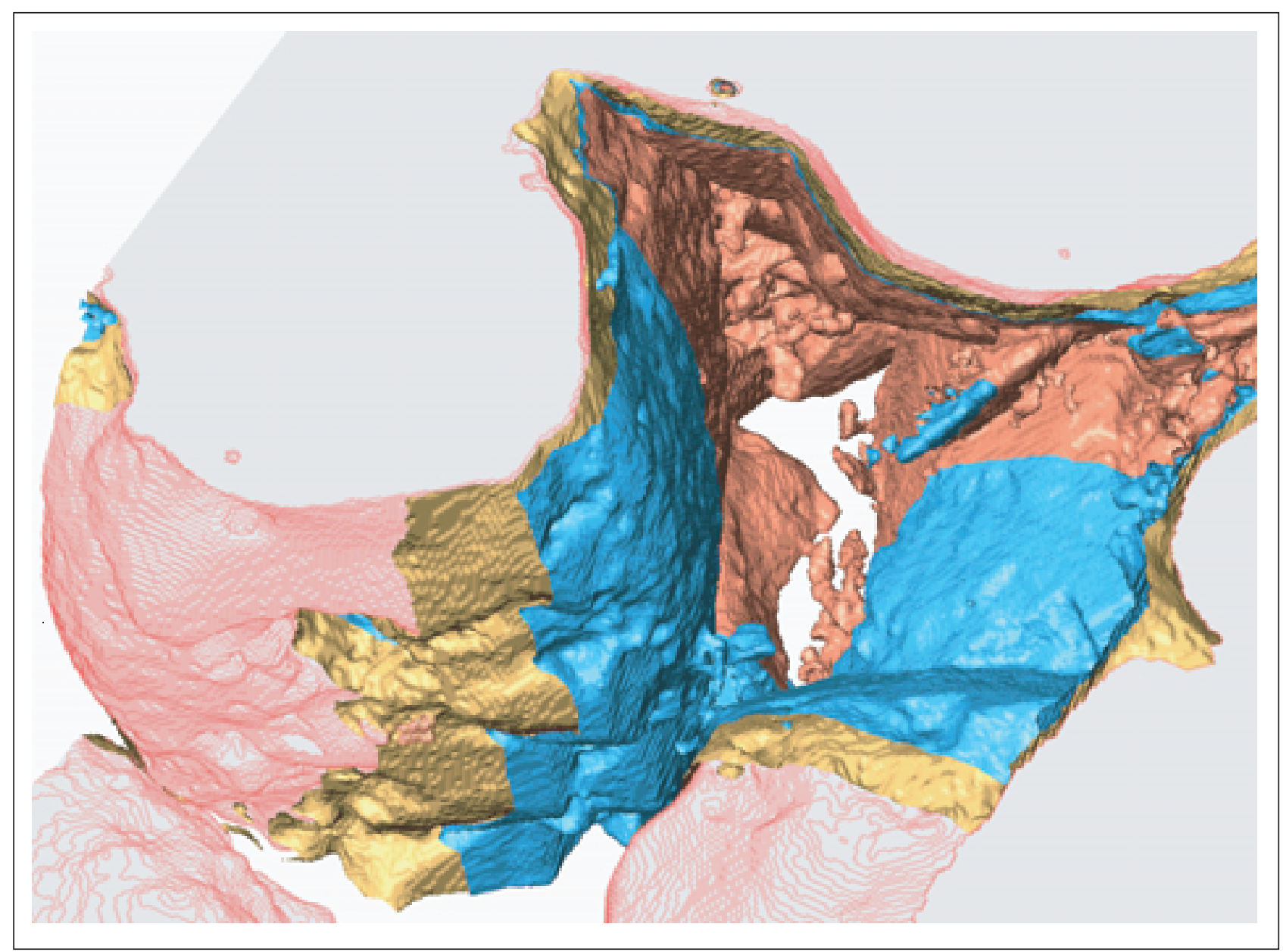

Figure 13

3D image where the positions of the fluid/solid interface are superimposed on an image of the solid phase at the final state (in grey and pink). Initial state in orange, after one percolation stage in blue, and after two percolation stages in yellow.

in the pores. Even if only one third of the sample has been scanned, the number of voxels in the pores is too large for a direct computation (there is four unknowns, 3 velocity components and pressure, for each voxel). To reach exploitable grid sizes, the original volumes $V_{0}$ to $V_{3}$ have been sub sampled by a factor 4: a sub-sampled voxel comprises 64 voxels of the initial size. The resulting volumes, $\mathrm{SV}_{0}$ to $\mathrm{SV}_{3}$, have been segmented and the portion of the pore space connecting the input and the output faces identified (Fig. 14). It is through this fraction of the pore space $\left(67.6 \%\right.$ in $\mathrm{SV}_{0}, 88.9 \%$ in $\mathrm{SV}_{1}, 95.3 \%$ in $\mathrm{SV}_{2}$, and $97.0 \%$ in $\mathrm{SV}_{3}$ ) that the reactive fluid flows during the percolation stages. Results of the direct computation of the permeability along the core axis are given in Table 3 as well as the experimental estimates.

The complete permeability tensor can be obtained by solving the closure problem associated with the volume averaging of Stokes equations, as described by Whitaker
TABLE 3

Permeability values calculated on a sub sampled 3D image of a portion of the core and measured during the reactive percolation stages

\begin{tabular}{l|c|c|c|c}
\hline $\begin{array}{c}\text { Permeability } \\
\left(\mu \mathbf{m}^{2}\right)\end{array}$ & Initial state & State 1 & State 2 & State 3 \\
\hline Calculated & 0.11 & 0.86 & 4.97 & 25.19 \\
Experimental & 0.04 & 0.31 & $>5.0$ & - \\
\hline
\end{tabular}

(1999). Although computationally demanding, the solution of this closure problem can be accomplished with established methods. Here we used a code where spatial discretisation is performed following the classical finite volume method on a staggered grid, and time integration is carried out using a fully explicit scheme for which a stability criterion has been developed. This program has been extensively used in 2D and 3D (Anguy et al., 1994; Bernard, 1995; Bernard and Vignoles, 2000) and has proved to be well suited for large 3D problems. 


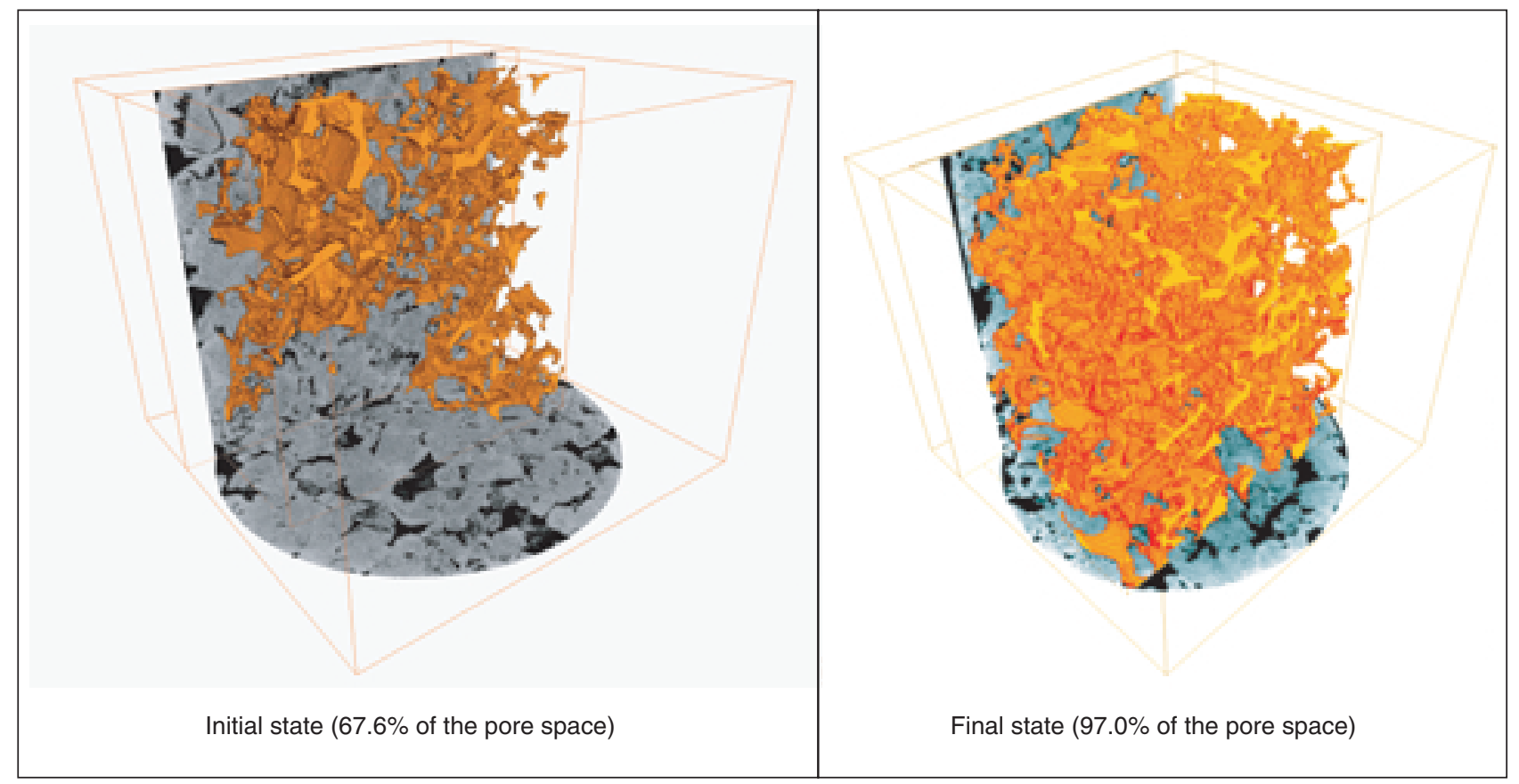

Figure 14

Partial views of the pore space connecting the upper and lower faces in the initial state (left) and in the final state (right). Permeability computations have been performed using those geometries.

Taking into account that:

- computation have been performed after a major sub sampling;

- computation only used one third of the sample (longitudinal heterogeneities are ignored);

- the portion of the sample that have been scanned is near the entrance of the reacting fluid and, consequently, it is the most altered zone;

this preliminary comparison can be considered encouraging.

\section{CONCLUSIONS}

In this paper two examples have been presented to illustrate the possibilities offered by synchrotron microtomography to quantitatively characterise the evolutions of porous materials.

In the first one, a minor absorbing phase is considered. Even if its volume fraction is too small to be put into evidence by classical X-ray diffraction methods, it has been precisely quantified. Furthermore the two shapes under which it appears (platelets and crystallites) have been distinguished and the morphological evolution of a single platelet followed.

In the second example, a portion of a limestone sample submitted to reactive percolation has been studied. After 3D registration of partial volumes, an original procedure has been applied to estimate the evolutions of the fluid/solid interface and of the effective reactive surface at the pore scale. Permeability estimates have been computed after sub sampling of the original 3D images obtained by synchrotron microtomography.

For microtomography, synchrotron is an X-ray source giving 3D images of very high quality. Accessibility to synchrotron is drastically limiting the possibilities for "classical" projects in the field of porous material evolutions. Micro-focus laboratory tomographs give images of lower quality but their progresses are very rapid (sub micronic pixel sizes are now proposed for this type of apparatus). Taking advantage of the complementarities between those two types of sources will surely be the way to promote the usage of microtomography in the numerous fields where it can be applied.

Precise and large 3D images can now be obtained. Several data treatment methods (3D registration), image analysis algorithms and numerical codes (permeability computation) reach their limit of applicability for those sizes. The classical methods must be adapted, if possible, and new methods have to be developed to fully take advantage of the volume of information now available through X-ray microtomography.

\section{ACKNOWLEDGEMENTS}

The author would like to thank Elodie Boller, Xavier Thibault, Peter Cloetens, and José Baruchel (ID 19, ESRF, 
Grenoble) for the scientific support concerning tomography experiments. Computations and visualisations have been made possible thanks to partial funding of the Conseil Régional d'Aquitaine, Bordeaux, France. The French project PICOR is also acknowledged for partial funding of the reactive percolation experiment.

\section{REFERENCES}

Anguy, Y., Bernard, D. and Ehrlich, R. (1994) The Local Change of Scale Method for Modelling Flow in Natural Porous Media (I): Numerical Tools. Advances in Water Resources, 17, 337-351.

Babout, L., Maire, E., Buffière, J.Y. and Fougères, R. (2001) Characterization by X-ray Computed Tomography of Decohesion, Porosity Growth and Coalescence in Model Metal Matrix Composites. Acta Mater., 49, 2055-2063.

Baruchel, J., Buffière, J.Y., Maire, E., Merle, P. and Peix G. (2000) X-ray Tomography in Material Science, Hermès Sciences Pub., Paris.

Bernard, D. (1995) Using the Volume Averaging Technique to Perform the First Change of Scale for Natural Random Porous Media. In: Advanced Methods for Groundwater Pollution Control, Gambolati \& Verri (Eds), CISM Courses and Lectures No. 364, Springer Verlag, Wien, 9-24.

Bernard, D. and Vignoles, G.L. (2000) In: Computational Methods for Flow and Transport in Porous Media, Crolet (Ed.), Kluwer Acad. Pub., Dordrecht, 217-229.

Bernard, D., Gendron, D., Bordère, S. and Heintz, J.M. (2001) First Direct 3D Visualisation of Micro Structural Changes During Sintering. ESRF Highlights 2001, 102-103.

http://www.esrf.fr/info/science/highlights/2001/applied/APPL2.html

Bernard, D., Gendron, D., Heintz, J.M., Bordère, S. and Etourneau, J. (2005a) First Direct 3D Visualisation of Micro Structural Evolutions During Sintering Through X-ray Computed Microtomography. Acta Materialia, 53, 121-128.

Bernard, D., Nielsen, Ø., Salvo, L. and Cloetens, P. (2005b) Permeability Assessment by 3D Interdendritic Flow Simulations on Microtomography Mappings of Al-Cu Alloys. Materials Science \& Engineering A, 392, 112-120.

Bernard, D., and Chirazi, A. Numerical Treatment of Ring Artefacts for the Microtomographic Image Reconstruction and Porous Media Characterisation, to be published.

Bordère, S., Bernard, D., Gendron, D. and Heintz, J.M. (2004) Characterization of Elementary Sintering Processes Using Monte Carlo Simulation and X-ray Computed Microtomography. In: Computational Methods in Materials Characterisation, Mammoli, A.A. and Brebbia, C.A. (Ed.), WIT press, Southampton (UK), 23-32.
Burlion, N., Bernard, D. and Chen, D. (2005) X-ray Microtomography: Application to Microstructure Analysis of a Cementitious Material During Leaching Process. Cement and Concrete Composites, in press.

Duliu, O.G. (1999) Computer Axial Tomography in Geosciences: an Overview. Earth-Science Reviews, 48, 265-281.

Gendron, D. (2001) Étude numérique et expérimentale du frittage à l'échelle du grain. Thèse, Université Bordeaux I.

German, R.M. (1996) Sintering Theory and Practice, WileyInterscience pub., New York.

Herman, G.T. (1980) Image Reconstruction from Projections: the Fundamentals of Computerized Tomography, Academic Press, New York.

Maintz, J.B.A., and Viergever, M.A. (1998) A Survey of Medical Image Registration. Medical Image Analysis, 2, 1, 1-36.

Mees, F., Swennen, R., Van Geet, M. and Jacobs, P. (2003) Applications of X-ray Computed Tomography in the Geosciences. Geol. Soc. Special Pub. No. 215, Geological Society, London.

Natterer, F. (1999) Numerical Methods in Tomography. Acta. Num., 8, 107-141.

Noiriel, C., Gouze, P. and Bernard, D. (2004) Investigation of Porosity and Permeability in Relation with Microstructure Changes During Limestone Dissolution. Geophys. Res. Lett., 31, L24603, doi:10.1029/2004GL021572.

Noiriel, C., Gouze, P., Bernard, D. and Thibault, X. (2005) Hydraulic Properties and Micro-geometry Evolution Accompanying Limestone Dissolution by Acidic water. Oil \& Gas Science and Technology - Revue de l'Institut Français du Pétrole, 60, 1, 177-192.

Peyrin, F., Salome, M., Cloetens, P., Laval-Jeanet, A.M., Ritman, E. and Rüegsegger, P. (1998) Micro-CT Examinations of Trabecular Bone Samples at Different Resolutions: 14 and 2 Micron Level. Technology and Health Care, IOS Press, 6, 5-6, 391-401.

Renard, F., Bernard, D., Thibault, X. and Boller, E. (2004) Synchrotron 3D Microtomography of Halite Aggregates During Pressure Solution Creep and Evolution of the Permeability. Geophys. Res. Lett., 31, 7, L07607 10.1029/2004GL019605, 3 April.

Stanley, J.H. (1988) Computed Tomography: the Physical and Mathematical Basis of a Powerful New Industrial Inspection Technique. ASTM Standardization News, 44-49.

Whitaker, S. (1999) The Method of Volume Averaging, Theory and Application of Transport in Porous Media, Vol. 13, Kluwer Acad. Pub., Dordrecht. 